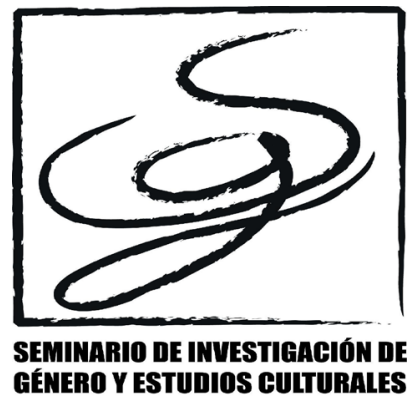

\title{
Número 7 (2020). Violencias contra las mujeres desde un enfoque artístico-literario y sociocultural
}

\author{
Rocío Cárdenas-Rodríguez \\ Universidad Pablo de Olavide, de Sevilla \\ mrcarrod@upo.es \\ Candelaria Terceño-Solozano \\ Universidad Pablo de Olavide, de Sevilla \\ ctersol@upo.es \\ Sergio Marín-Conejo \\ Universidad Pablo de Olavide, de Sevilla \\ smarin@upo.es
}

Las consecuencias de la sociedad patriarcal se manifiestan en todos los ámbitos de la vida, siendo patente la desigualdad y las brechas de género que sitúan a las mujeres en un plano de inferioridad con respecto a los hombres. Esta situación se evidencia en la sociedad en todas las esferas, como por ejemplo, en las familias, el sistema educativo, los medios de comunicación, las empresas, etc., así como en las representaciones artísticas y literarias que se han realizado de las mujeres a lo largo de la historia.

Los seres humanos, a través del arte, representamos nuestra idea de la vida, nuestras expectativas, deseos, miedos, con finalidades estéticas, comunicativas, adoctrinadoras, reivindicadoras, pero siempre con una cualidad común, que llegue al espectador y que provoque un efecto en el mismo. De esta forma, a lo largo de la historia, los seres humanos han representado a las mujeres con todos los patrones culturales que en cada época ha impuesto, pudiéndose observar en las representaciones artísticas y literarias elementos de discriminación hacia la mujer, violencia de género, agresiones físicas, sexuales, psicológicas, favoreciendo esa desigualdad de género presente en las sociedades.

A través de las representaciones artísticas que se han ido sucediendo a lo largo de los siglos, se ha representado a la mujer con un papel pasivo en el arte, siendo modelo o musa de los artistas masculino, cualquier experiencia de mujeres artísticas se han visto invisibilizadas 0 en algunos casos desprestigiadas, sufriendo estas mujeres artistas el menosprecio de la sociedad. Sin embargo, a partir de los años 80, a través del movimiento feminista, se han venido desarrollado una importante actividad artística de cambio y transformación social a través 
del arte, siendo el arte una herramienta importante de empoderamiento femenino y de lucha por los derechos de las mujeres.

La autora Alario Trigueros (2008) sostiene que el feminismo ha existido siempre, ya que en cualquier acción en el que las mujeres han desafiado su situación y han reivindicado un cambio de la misma, ha estado la lucha por los derechos de las mujeres. Como ejemplo, Alario (2008) menciona mujeres en la Edad Media como las religiosas Hildegarda de Bingen (compositora, escritora, filósofa) y Herrada de Landsberg (autora de enciclopedias pictóricas) que han desarrollado importantes proyectos culturales y artísticos denunciando la misoginia por parte de los hombres, si bien, muchos de sus productos artísticos de estas mujeres y de otras no han llegado hasta nosotras, solo sus nombres, siendo invisibilizadas por los historiadores.

El presente número de la revista Ambigua, Revista de investigaciones sobre género y estudios culturales, pretende analizar las violencias sexuales y de género de un modo integral y multidisciplinar, para comprender las distintas formas de violencia que han sufrido y sufren las mujeres. Para ello se realiza un abordaje multidisciplinar analizando distintos elementos que influyen y están presentes en la violencia contra las mujeres, prestando especial atención a las manifestaciones que se desarrollan desde las prácticas artísticas colectivas y otras expresiones literarias y humanísticas.

En esta línea el texto de Cagnolatti visibiliza a una de las autoras más importantes de la literatura italiana de finales del siglo XIX y principios del XX, como fue Paola Drigo (1876 - 1938). Esta autora realiza una análisis reflexivo de sus obras así como la realidad de las mujeres en la sociedad burguesa, centrándose en la novela María Zef y las consecuencias de esta novela entre los lectores de la época, por transgredir las normas sociales y escribir sobre temas tabú de esa época, siendo protagonistas de esta obra tres personajes femeninos.

Como hemos mencionado, la sociedad y los poderes públicos suelen invisibilizar las prácticas emancipadoras que las mujeres han desarrollado a lo largo de la historia y permanecer impasible ante la violencia hacia las mujeres, y así lo pone de manifiesto Suárez Lafuente en su análisis de ejemplos literarios donde refleja cómo la opinión pública y la sociedad reaccionan ante la violencia contra las mujeres, este autor analiza a través de las obras de distintos autores la situación de dependencia de las mujeres, la desigualdad de género y cómo la sociedad justifica esta desigualdad.

Por su parte, Leonardo-Loayza analiza el poemario escrito por una autora peruana que analizó la violencia sufrida por las mujeres y ejercidas por los aparatos de opresión del Estado. Es importante su contribución ya que da voz a las propias mujeres contando en primar persona sus experiencias y la represión violenta vivida en el contexto de una guerra interna donde fueron consideradas objetos sexuales. Este análisis se sitúa en la violencia política y sexual que sufren las mujeres en las guerras, así como el impacto en su desarrollo personal, narrando en primar persona sus vivencias. 
Otra de las artes escénicas que ha visibilizado la situación de las mujeres ha sido el cine, y así lo manifiesta Pérez García en su obra, donde analiza las consecuencias que tiene para las mujeres la violencia que se ejercen sobre ellas, a través del análisis de la película "El último tren de Gun Hill" de 1959, donde un hombre lleva a cabo una venganza por la violación y el asesinato de su mujer, En este artículo el autor analiza las estrategias utilizadas por el director de la película al utilizar el personaje femenino para darle voz a todo lo vivido por ella, siendo éste un recurso cinematográfico muy utilizado por este director.

Estos capítulos, donde se analizan las manifestaciones artísticas que presentan y representan el papel de la mujer en una época determinada, la violencia que sufren las mujeres y las desigualdades de género, expresadas a través de la literatura, el cine, la música, son importantes para visibilizar toda la producción artística y literaria que contribuye a la sensibilización social y a crear conciencia social ante estas desigualdades, sin embargo, es necesario seguir avanzando en el planteamiento del arte y de sus representaciones artísticas como estrategias de empoderamiento y de intervención socioeducativa, continuar trabajando en el arte como estrategia de intervención social para favorecer los procesos de cambio y la constitución de una sociedad en igualdad de género.

Además de esta primera selección, este número se completa con una serie de estudios relacionados con el tema central como el trabajo de reflexión de Pam Rodríguez Pérez sobre la categoría de víctima en los casos de violencia sexual teniendo en consideración la complejidad que supone un marco de compresión multidisciplinar donde intervienen además procesos psicológicos. En este ámbito de las diversidades en el encuadre de la violencia, la literatura ofrece representaciones alternativas de poder femenino. Maravillas Moreno Amor y José Miguel Rojo Martínez analizan Lisístrata, de Aristófanes; Cien Años de Soledad, de Gabriel García Márquez y El País de las Mujeres, de la nicaragüense Gioconda Belli, para extraer planteamientos teóricos sobre esta idea de matriarcado.

También como forma de violencia, simbólica en términos bourdieuanos aplicada al par genialidad-locura, Renata Bega Martínez presenta la "locura" asociada tradicionalmente a la mujer como rol fundamental en el contexto del por sí ya violenta sociedad occidental en la que el varón se beneficia, de la misma forma, del otro par mediante un proceso de "censura identitaria". No es de extrañar que, como nos muestra Silvia Gas Barrachina, se produzcan "narrativas estéticas como política de resistencia". La autora se centra en el caso hondureño, donde la violencia jerarquizada, cuya respuesta suele ser la impunidad, recibe una respuesta política en forma de activismo artístico como forma de expresión de un código complejo estético con finalidad transformadora.

Una respuesta similar se puede percibir desde la literatura camerunesa. Pierre Suzanne Eyenga Onana nos ofrece un trabajo en francés dividido en tres partes: formas de violencia contra la mujer, la estética de la violencia sexual, en la segunda, y el mensaje de algunas obras en relación con la agresión sexual para terminar. 
Otro de los artículos aceptados para la sección de estudios, trata la percepción del abuso infantil destilado desde el legado patriarcal y adultocéntrico con el prisma de las víctimas, el abusador y quien ejerce de testigo. Tras realizar grupos de discusión en los municipios de Aquitania y Chitaraque del departamento de Boyacá, Colombia se extraen mecanismos performativos y socioculturales que legitiman la violencia que se ejerce contra las niñas.

En relación con la niñez, Begoña Gonzáles Rodríguez, trata cuatro trabajos de la autora italiana Dacia Maraini y el rol de la madre ante el abuso sexual infantil ya sea como colaboradora necesaria, ignorante o silenciosa, o sea protectora, rebelde pero silenciadas. En este complicado entramado de violencia familiar, menores y madres comparten espacio, tiempo, pero también culpa, de forma que puede llegarse a la autodestrucción.

Se cierra esta sección con la aportación de Diego Ernesto Parra Sánchez sobre la novela policíaca Amorosos fantasmas del mexicano Paco Ignacio Taibo II donde se describe la violencia ejercida contra la mujer en contextos urbanos con el rol de la prostituta y el padrote, como se conoce en el argot al proxeneta.

Aún quedan dos series de artículos para la sección varia y cuatro reseñas que esperamos sean de igual interés.

\section{Referencias Bibliográficas:}

Alario Trigueros, Maria Teresa. Arte y feminismo (Vol. 22). Editorial NEREA. 2008. 
Ambigua, Revista de Investigaciones sobre Género y Estudios

Culturales, n. ${ }^{\circ} 7,2020$, pp. 1-5. ISSN: 2386-8708 